\title{
ГРАНТ - ПУБЛИЧНЫЙ ИНТЕРЕС, РЕАЛИЗУЕМЫЙ В ЧАСТНОЙ ИНВЕСТИЦИИ
}

\section{GRANT - PUBLIC INTEREST REALIZED IN PRIVATE INVESTMENT}

\begin{abstract}
Based on the results of the analysis of the legal nature of the grant as a financial instrument providing support for scientific research in the Russian Federation, some practical problems arising in the process of issuing and using grants, as well as the fulfillment of obligations by the beneficiaries, are identified. One of the reasons is the apparent contradiction of public and private interests of participants of public relations arising in the process of implementation of grant activities at all stages, including relations of grantees with their organizations - employers, as well as with the organization providing the conditions for the implementation of a research project. It was concluded that it is necessary to form a separate independent legal institution of the grant as an integrated legal education, as well as conceptual improvement of the legal regulation of grant activities, through the adoption of a special federal law "On Grants and Grant Activities".
\end{abstract}

Keywords: grant, grantor, grantee, competition, funding, commitments, research

Ключевые слова: грант, грантодатель, грантополучатель, конкурс, финансирование, обязательства, научные исследования

\section{Введение}

Вместе с научно-техническим прогрессом и крайне динамичным развитием общественных отношений во всех сферах в нашу жизнь прочно вошла такая форма безвозмездного финансирования осуществления научно-исследовательской деятельности как грант. Гранты на осуществление конкретных научных, научно-технических программ и проектов, инновационных проектов, проведение конкретных научных исследований не только получили широкое применение в практике организации отечественной науки, но гранты как финансово-хозяйственный инструмент стали использоваться во многих других областях жизнедеятельности. Вместе с там законодательная регламентация, равно как и правовая доктрина регулирования взаимоотношений сторон грантовой деятельности по назначению, выдаче, получению и использованию грантов практически отсутствует, а спорные вопросы решаются на основании локальных правовых актов либо по аналогии закона или даже права. Это снижает эффективность рассматриваемого средства интенсификации научно-технического развития и института реальной экономики.

Для формирования должной правовой основы осуществления грантовой поддержки научных исследований в Российской Федерации нужно, прежде всего, выявить необходимые и достаточные пределы правового воздействия на общественные отношения, возникающие при финансировании науки посредством предоставления грантов как на национальном, так и международном уровнях. А они обусловлены реальной конфликтностью и проблемами реализации 
грантов, о чем свидетельствует также достаточно большое количество научных публикаций [Артемова 2016 , с. 55-60; Бабина 2014, с. 170-173; Провалинский 2017, с. 139-145]. Цель настоящей статьи - раскрыть некоторые из таких проблем и предложить их регулятивное решение.

\section{Правовая природа гранта}

Советская система сметно-бюджетного финансирования науки не нуждалась в дополнительных источниках, наука в тот период была поставлена на достаточно высокий уровень, научно-технический потенциал признавался одним из самых значительных в мире. В перестроечные времена в условиях критического недофинансирования и нарушения устойчивых связей научная система в России претерпела определенную дезорганизацию, разрушение научно-экспертного сообщества - среды научного общения, самоизоляцию научных учреждений, фактическую утрату многие годы выстраиваемых научно-производственных коопераций.

Первые гранты на проведение или продолжение ранее начатых научных исследований стали предлагаться российским ученым из-за рубежа. Позже в России также начал воплощаться заимствованный зарубежный опыт финансовой поддержки науки в форме грантов и иных видов безвозмездного финансирования от фондов и других организаций общественного блага.

Грант, будучи словом, английского происхождения, буквально означает не просто дар, а деньги, данные кому-либо с конкретным назначением. То есть, с одной стороны, это денежные средства, выдаваемые безвозмездно и безвозвратно, с другой стороны, это всегда целевые денежные средства, осваивание которых подразумевает получение общественно-полезного результата.

Понятие гранта не связано с осуществлением финансирования только в сфере научно-исследовательской деятельности, опытно-конструкторских и технологических работ. Отечественной практике известны иные виды грантов, в том числе направленные на реализацию программ в области культуры, искусства, образования, физической культуры, охраны здоровья, другие социально значимые цели, гранты для поддержки инновационных проектов, молодых ученых, малого бизнеса и т.п. [Провалинский 2016, с. 11-12].
Более того, сама идея осуществления спонсорской деятельности по финансированию научных проектов была популярна и широко практиковалась в дореволюционной России [Медведев 2016, с. 186].

Среди известных российскому финансовому праву институтов грант наиболее схож с субсидией, также характеризуется безвозмездной передачей средств и целевым характером. Его финансово-правовая природа и определила начальное правовое регулирование в российском праве в совместном письме Госналогслужбы России № ЮУ-4-06/88н, Минфина России № 04-06-01 от 11 июня 1993 г. «О порядке налогообложения грантов, получаемых от иностранных благотворительных организаций».

Грант как легальное общественное отношение был признан в Федеральных законах от 19 мая 1995 г. № 82Ф3 «Об общественных объединениях» и от 11 августа 1995 г. № 135-Ф3 «О благотворительной деятельности и добровольчестве (волонтерстве)». А в Федеральном законе от 23 августа 1996 г. № 127-ФЗ «О науке и государственной научно-технической политике» было дано его определение, в соответствии с которым применительно к финансированию научно-исследовательских работ под грантами понимаются денежные и иные средства, передаваемые безвозмездно и безвозвратно на осуществление конкретных научных, научно-технических программ и проектов, инновационных проектов, проведение конкретных научных исследований на условиях, предусмотренных грантодателями.

Основы правового режима грантов как финансового инструмента в форме субсидий были заложены в Федеральном законе от 2 июля 2013 г. № 181-Ф3 «О внесении изменений в статьи 78 и 78.1 Бюджетного кодекса Российской Федерации в части предоставления грантов». Вопросы налогообложения грантов в целом разрешены в Налоговом кодексе Российской Федерации.

Отдельные спорные вопросы, касающиеся порядка назначения грантов на научно-исследовательские работы, были урегулированы в Правилах предоставления грантов в форме субсидий из федерального бюджета, выделяемых для государственной поддержки научных исследований, проводимых под руководством ведущих ученых в российских образовательных организациях высшего образования, научных учреждениях и государственных научных центрах Российской Федерации, утвержденных постановлением Правительства Российской Федерации от 8 мая 2019 г. № 576. 
Известны примеры правового регулирования вопросов грантовой поддержки науки на уровне субъектов Российской Федерации, например: Закон Волгоградской области от 4 марта 2005 г. № 1020-ОД «О государственных научных грантах Волгоградской области». И даже в отдельно взятой корпорации (Положение о научных грантах президента ОАО «РЖД» для поддержки молодых ученых). Однако в целом на общефедеральном уровне нет нормативного правового акта, сколько-либо универсально регламентирующего весь спектр общественных отношений, возникающих в процессе назначения, выдачи и использования грантов в целях финансирования научных исследований.

В то же время грант представляет собой не только безвозмездную и безвозвратную субсидию, но и основание для возникновения многостороннего правоотношения, где на стороне грантополучателя лежит обязательство выполнения научного исследования, на которое грант был предоставлен, с последующим отчетом как о результатах исследования, так и о об использовании предоставленных на него денежных средств.

В Гражданском кодексе Российской Федерации наиболее близкими по обязательственно-правовой природе являются институт публичного конкурса (статье 1057-1061 ГК РФ) и институт дарения, а именно - пожертвование (статья 582 ГК РФ). Но ни тот, ни другой по своей сущности не отражают правовую природу гранта.

\section{Интересы участников грантового правоотношения}

Поскольку грант на проведение научно-исследовательских работ - это денежные средства, которые передаются безвозмездно и безвозвратно гражданами и юридическими лицами, в том числе иностранными гражданами и иностранными юридическими лицами, а также международными организациями, получившими право на предоставление грантов на территории Российской Федерации, то указанные субъекты - грантодатели - должны быть заинтересованы в получении научного или научно-технического результата.

Как правило, грантовую поддержку находят научные проекты, направленные на получение новых знаний о природе, человеке и обществе. Такие научные проекты способствуют научно-техническому прогрессу и приносят пользу обществу. Конкурс на получение гранта является публичным, что предполагает негласный общественный контроль над тематикой научных исследований. Таким образом, грантодатель, финансируя научно-исследовательскую деятельность, удовлетворяет не только частный, но, прежде всего, публичный интерес.

Грантополучателями в зависимости от условий конкурса могут являться физические лица - как граждане Российской Федерации, так и иностранцы, и лица без гражданства, а также коллективы, состоящие из физических лиц, либо юридические лица. Часто в соответствии с объявленными требованиями к участникам конкурса в нем могут принимать участие именно коллективы с оговоренной грантодателем рамочной численностью. С этой точки зрения гранты - отличная возможность для формирования временных научных коллективов, не связанных одним работодателем, но объединенных общим научным интересом.

Если в соответствии с условиями гранта научно-исследовательская работа рассчитана на продолжительный период, например, на несколько лет с обязательными ежегодными промежуточными отчетами и возможностью пролонгации срока, такие научные группы могут обладать также мобильностью, что позволяет в определенной степени динамично реагировать на состав ученых в грантовой группе в интересах получения наилучшего конечного результата исследования.

Выиграть конкурс на получение гранта на проведение научно-исследовательской работы абсолютно любое физическое лицо, очевидно, не может - как правило, это удается уже сложившимся специалистам в сфере научного проекта, являющимся научными работниками, работающими в научных, научно-исследовательских учреждениях, образовательных организациях и профессионально занимающимся научными исследованиями в данной области. Право на участие в конкурсах на получение грантов на проведение научных исследований - не только неотъемлемая составляющая правового статуса научного работника, но и их прямой частный интерес на получение дополнительного финансирования своей профессиональной деятельности, а также возможность вести альтернативные научные исследования.

Зачастую участниками грантовых коллективов по научным проектам становятся также педагогические работники, составляющие профессорско-преподавательский состав образовательных организаций и занимающиеся наукой параллельно с осуществлением 
образовательной деятельности. Для них научная деятельность - это вторичная занятость, однако проведение научных исследований с последующей защитой диссертаций является неизбежным сопровождением успешной карьеры любого преподавателя, поэтому они составляют достойную конкуренцию научным работникам в конкурсах на получение научных грантов.

При этом в России всегда на достаточно высоком уровне была развита добровольческая и неформальная наука. Только каждый ли «Кулибин» может не только принять участие в конкурсе на получение научного гранта, но и выиграть его?

В настоящее время в нашей стране два научных фонда получают из федерального бюджета денежные средства для организации осуществления фундаментальных научных исследований. Во-первых, это Российский научный фонд (далее - РНФ). В качестве цели деятельности РНФ в пункте 1 статьи 2 Федерального закона от 2 ноября 2013 г. № 291-Ф3 «О Российском научном фонде и внесении изменений в отдельные законодательные акты Российской Федерации» указывается финансовая и организационная поддержка фундаментальных научных исследований и поисковых научных исследований, подготовки научных кадров, развития научных коллективов, занимающих лидирующие позиции в определенной области науки. Таким образом, РНФ осуществляет не только проектное финансирование, поддерживая конкретные научные исследования, но и институциональное, направленное на развитие научных коллективов и подготовку научных кадров в целом.

В частности, РНФ разработана Президентская программа исследовательских проектов, реализуемых ведущими учеными, в том числе молодыми учеными в соответствии с пунктом 11 Перечня поручений Президента Российской Федерации от 5 декабря 2016 г. № Пр-2346 по реализации Послания Президента Российской Федерации Федеральному Собранию Российской Федерации. Цель Программы - содействие формированию в Российской Федерации передового сектора фундаментальных и поисковых исследований, пользующегося мировым признанием; развитие кадрового потенциала российской науки; участие в создании эффективной системы наращивания и наиболее полного использования интеллектуального потенциала нации.

Для того, чтобы принять участие в каком-либо из научных конкурсов, проводимых РНФ, необходимо зарегистрироваться в его информационно-аналитической системе (далее - ИАС РНФ), однако уже при регистрации в ИАС РНФ в качестве обязательной опции требуется указать зарегистрированную в системе организацию, с которой физическое лицо связано трудовыми отношениями, и от такой организации должен быть назначен координатор по участию в конкурсах РНФ.

Другим таким фондом является Федеральное государственное бюджетное учреждение «Российский фонд фундаментальных исследований» (далее РФФИ). РФФИ призван финансировать конкретные научные проекты в непосредственном взаимодействии с учеными-исследователями. Основная задача РФФИ - проведение конкурсного отбора лучших научных проектов из числа тех, что представлены Фонду учеными в инициативном порядке, и последующее организационно-финансовое обеспечение поддержанных проектов посредством грантов [Белявский 2018, с. 175-176].

При регистрации в Корпоративной информационно-аналитической системе РФФИ (КИАС РФФИ) гражданин обязан предоставить информацию о себе и о своей работе. Есть вариант заполнения личных данных об основном месте работы: «в настоящее время не работаю в Российской Федерации». Однако большинство конкурсов, объявляемых РФФИ, подразумевает участие в грантовом правоотношении еще одного субъекта - организацию, предоставляющую условия для реализации проекта. Как правило, это должно быть указанное участником конкурса в заявке российское юридическое лицо - государственная организация, осуществляющая научную и (или) научно-техническую деятельность, которое предоставит научному коллективу условия для реализации проекта в случае предоставления гранта.

Таким образом, с одной стороны, право на получение научного гранта имеет каждое лицо, имеющее интерес в осуществлении научно-исследовательского проекта. С другой стороны, реально участвовать в конкурсах, проводимых РНФ и РФФИ, а тем более выигрывать их могут только сотрудники научных, научно-исследовательских и образовательных организаций, репутационно зарекомендовавших себя в сфере предполагаемого научного проекта.

Организация, предоставляющая условия для реализации проекта, является одной из сторон трехстороннего договора, заключаемого РФФИ с победителями 
конкурса. Чаще всего эта организация является работодателем если не всех членов научного коллектива, то по крайней мере его руководителя и большинства из них. Однако несмотря на то, что от такой организации было получено согласие предоставлять условия для реализации проекта еще до подачи заявки для участия в конкурсе, впоследствии ее интересы как работодателя зачастую не совпадают с интересами грантополучателей.

Поскольку отношения грантополучателя со своим работодателем урегулированы нормами трудового права, включая установленный законом лимит времени на труд и на отдых, грантополучатель должен выполнять работы по научному проекту в нерабочее время, например, в выходные дни, взяв очередной оплачиваемый отпуск или отпуск за свой счет. В том числе, если для получения результатов исследования необходимо выполнять работы за пределами населенного пункта, в котором трудится грантополучатель, или принимать участие в иногородних конференциях для апробации таких результатов.

Проведение научно-исследовательской работы в рамках финансируемого за счет гранта проекта - фундаментальная деятельность, требующая серьезных временных и трудовых затрат в ущерб другим видам профессиональной деятельности ученых и личному времени, что становится ясным даже на этапе подготовки на подготовки грантовой заявки [Стрельцова 2014 , с. 169-170]. В то же время, руководители организаций и подразделений, в которых трудятся научные работники, ставшие грантополучателями, зачастую не связаны общими целью и источником финансирования. Это, с одной стороны, может порождать различного рода коллизии в трудовых отношениях, а с другой - не способствует качественному проведению научно-исследовательской работы, финансируемой за счет гранта, и, как следствие, нивелирует публичный интерес грантодателя.

Порядок взаимодействия грантополучателей и организаций, предоставляющих условия для реализации научного проекта, может быть закреплен на уровне локального правового акта или соглашения между организацией, предоставляющей условия для реализации проекта, и грантополучателями - в какое время они вправе проводить работы, использовать специальное оборудование, привлекать к эксплуатации специального оборудования иной обслуживающий персонал, как оплачивать работу обслуживающего персонала и т.д. [Артемова 2016, с. 58-59]. В отсутствие такого соглашения или локального правового регулирования неизбежна конфликтность при реализации грантовых проектов.

Для тех организаций, чьи сотрудники систематически выигрывают конкурсы на получение научного гранта, характерно наличие именно локального правового акта. Например, приказом Московского государственного университета имени М.В. Ломоносова 12 марта 2018 г. № 270 утвержден Порядок выполнения проектов, поддержанных Российским фондом фундаментальных исследований; приказом Уфимского государственного авиационного технического университета 29 мая 2017 г. № 907-О утвержден Порядок организации обеспечения условий для реализации научных проектов грантополучателями (физическими лицами) РФФИ и учета расходов.

В целом же противоречия в интересах участников грантовых правоотношений в сочетании с неурегулированностью на федеральном уровне общественных отношений, возникающих между различного рода субъектами в связи получением и использованием научного гранта, и неопределенностью правового режима собственно гранта представляют собой серьезную проблему для дальнейшего развития российской науки.

\section{Выводы}

Грант на проведение научного исследования воспринимается, прежде всего, как финансовый инструмент, но общественные отношения, возникающие в связи с его назначением, выдачей и использованием, лежат в сферах правового регулирования самых разных отраслей права - гражданского, административного, бюджетного, налогового, трудового. Таким образом концепция совершенствования правового регулирования грантовой деятельности должна предполагать формирование отдельного самостоятельного межотраслевого правового института как комплексного правообразования.

В основу такой концепции необходимо заложить принципиальное понимание источников финансирования современной российской науки - как фундаментальных и поисковых научных исследований, так и инициативных исследовательских проектов, новаторских тем и проблем, которым еще не было уделено сколько-либо значительного внимания со стороны 
научного сообщества. При этом очевидно, что гранты выполняют роль дополнительного финансового стимулирования научного труда. А фундаментальная наука в стране должна развиваться за счет средств федерального бюджета, предоставляемых в полном объеме.

Одним из способов реализации концепции формирования правового института грантовой деятельности и совершенствования правового регулирования возникающих в процессе ее осуществления общественных отношений может стать принятие федерального закона «О грантах и грантовой деятельности».

\section{Библиография}

Артемова И.В. (2016), Организация трудовой деятельности в рамках гранта, «Советник в сфере образования» по. 1.

Бабина К.И. (2014), Грант как один из способов финансирования научных учреждений: особенности, проблемы, перспективы, «Вестник Саратовского государственного социально-экономического университета» no. 5 .

Белявский О.В. (2018), Проблемы правового регулирования грантовой поддержки фундаментальных научных исследований в Российской Федераиии, «Труды Института государства и права Российской академии наук» no. 4.

Медведев И.П. (2016), Румянцевский грант императорской Академии наук на издание русских тетописей, «Петербургский исторический журнал: исследования по российской и всеобщей истории» no. 1.

Провалинский Д.И. (2016), Отечественные гранты и их виды, «Право и государство: теория и практика» по. 10.

Провалинский Д.И. (2017), Некоторые проблемы реализачии отечественных грантов и пути их оптимизаизии, «Правовая политика и правовая жизнь» no. 3.

Стрельцова Е.А. (2014), Негативные последствия грантозависимости современной науки, «Вестник Санкт-Петербургского университета. Серия 12. Социология» no. 1.

\section{Список правовых актов}

Федеральный закон от 11 августа 1995 г. № 135-Ф3 «О благотворительной деятельности и добровольчестве (волонтерстве)» (СЗ РФ, 1995, N 33, ст. 3340).
Федеральный закон от 19 мая 1995 г. № 82-Ф3 «Об общественных объединениях» (СЗ РФ, 1995, N 21, ст. 1930).

Гражданский кодекс Российской Федерации (часть вторая) от 26 января 1996 г. № 14-ФЗ.

Федеральный закон от 23 августа 1996 г. № 127-Ф3 «О науке и государственной научно-технической политике» (СЗ РФ, 1996, N 35, ст. 4137).

Бюджетный кодекс Российской Федерации от 31 июля 1998 г. № 145-Ф3.

Налоговый кодекс Российской Федерации (часть вторая) от 5 августа 2000 г. № 117-ФЗ.

Закон Волгоградской области от 4 марта 2005 г. № 1020ОД «О государственных научных грантах Волгоградской области».

Федеральный закон от 2 июля 2013 г. № 181-Ф3 «О внесении изменений в статьи 78 и 78.1 Бюджетного кодекса Российской Федерации в части предоставления грантов» (СЗ РФ, 2013, N 27, ст. 3473).

Федеральный закон от 2 ноября 2013 г. № 291-Ф3 «О Российском научном фонде и внесении изменений в отдельные законодательные акты Российской Федерации» (С3 РФ, 2013, N 44, ст. 5630).

Перечень поручений Президента Российской Федерации по реализации Послания Президента Федеральному Собранию от 5 декабря 2016 г. № Пр-2346.

Постановление Правительства Российской Федерации от 8 мая 2019 г. № 576 «О внесении изменений в акты Правительства Российской Федерации и признании утратившими силу некоторых актов Правительства Российской Федерации».

Письмо Госналогслужбы России № ЮУ-4-06/88н, Минфина России № 04-06-01 от 11 июня 1993 г. «О порядке налогообложения грантов, получаемых от иностранных благотворительных организаций» (Бюллетень нормативных актов министерств и ведомств РФ, 1993, N 9).

Положение о научных грантах президента ОАО «РЖД» для поддержки молодых ученых (Бюллетень Объединенного ученого совета ОАО РЖД, 2010, N 1).

Приказом Уфимского государственного авиационного технического университета от 29 мая 2017 г. № 907O «Об утверждении Порядка организации обеспечения условий для реализации научных проектов грантополучателями (физическими лицами) РФФИ и учета расходов».

Приказ Московского государственного университета имени М.В. Ломоносова от 12 марта 2018 г. № 270 «O порядке выполнения проектов, поддержанных Российским фондом фундаментальных исследований». 